This is a peer-reviewed, accepted author manuscript of the following paper: Emdadi, S., Hossein Sorouraddin, M., \& Dennany, L. (2020). Enhanced chemiluminescence determination of paracetamol. Analyst. https://doi.org/10.1039/DOAN01557A

\title{
Enhanced Chemiluminescence Determination of Paracetamol
}

\begin{abstract}
Simin Emdadi, *a Mohammad Hossein Sorouraddin ${ }^{a}$ and Lynn Denanny ${ }^{b}$
Due to severe consequences of potential overdoses from paracetamol (PCM) on the human body, the measurement of PCM in the pharmaceutical and the biological samples is essential. Therefore, presenting a simple and rapid technique with high detection limit and wide linear range plays a crucial role in detecting the PCM's overdose leading to drug poisoning. This contribution illustrates a novel chemiluminescence $(\mathrm{CL})$ system for the detection of PCM based on the chemiluminescent reaction between $\mathrm{PCM}$ and $\mathrm{KMnO}_{4}$. An enhanced $\mathrm{CL}$ was observed by the addition of rhodamine.6G within an SDS surfactant. The system demonstrates good analytical performance over the linear range $0.12 \mu \mathrm{M}$ to $0.185 \mathrm{mM}$ with a detection limit of $7.8 \times 10^{-8} \mathrm{M}$. In addition, good precision was observed with a RSD of $0.81 \%$. This system was successfully applied to the detection of PCM in pharmaceutical tablets and drop as well as from human urine samples with average \% recoveries ranging from 95.5 to $105.7 \%$. Possible interferences from major excipients in pharmaceuticals and other related compounds as well as biological interferences were also studied. This highlights the feasibility of the proposed system for real sample analysis in both chemical and biological matrices.
\end{abstract}

\section{Introduction}

Paracetamol (PCM), ( $\mathrm{N}$-acetyl-4-aminophenol), is a common antipyretic and analgesic drug. ${ }^{1}$ It has been formulated in the many pharmaceutical tablets as the sole active ingredient or with other operative drugs such as caffeine, codeine phosphate or phenylephrine. ${ }^{2}$ Determination of the amount of PCM is essential given the possibilities for overdose and the toxic metabolite accumulation that can cause hepatic toxicity and renal failure. ${ }^{3}$ For example, hepatic toxicity can be observed when plasma levels of $\mathrm{PCM}$ are in the $120 \mu \mathrm{g} / \mathrm{mL}$ range $4 \mathrm{~h}$ after the consumption, while the serious damage can occur when plasmatic levels are at $200 \mu \mathrm{g} / \mathrm{mL}$ over the same time frame. ${ }^{3,4}$ Therefore, assessment of the level of PCM in any matrix, including tablet, oral drop formulation and biological samples, is crucial to evading and/or avoiding the possible side effects of overdoses.

Luminescence is described as emitting radiation by atom or molecule when it returns to the ground state from the excited state. ${ }^{5}$ The chemiluminescence $(\mathrm{CL})$ analysis is a method for the determination of emitting radiation by the reaction of a $\mathrm{CL}$ reagent (the inhibitor, the activator) with the analyte. Therefore, measurement of the intensity of emitting radiation is employed for the analytical purpose $^{6}$ and has shown to be effective for the detection of PCM. ${ }^{5,7}$

Several analytical methods have been presented for the measurement of PCM, such as: fluorimetry, ${ }^{8}$ electrochemical, ${ }^{9-13}$ spectrophotometry, ${ }^{14-16}$ flow injection analysis (FIA), ${ }^{17,}{ }^{18}$ chromatography, ${ }^{19-21}$ and capillary electrophoresis. ${ }^{22} \mathrm{CL}$ can offer several advantages over these methods such as: the innate high sensitivity, low noise, low detection limit, and wide dynamic range. ${ }^{23}$ As such, $\mathrm{CL}$ has been used to the analysis of the various important analysts. ${ }^{24-27}$ The system luminol- $\mathrm{H}_{2} \mathrm{O}_{2}-\mathrm{Fe}(\mathrm{CN})_{6}{ }^{3-}$ was presented for the first time for the indirect measurement of PCM. ${ }^{28}$ Besides, different $\mathrm{CL}$ systems were reported for the determination of $\mathrm{PCM}$, for example, $\mathrm{CL}$ system of tris (2,2'-bipyridyl) ruthenium (II)- $\mathrm{KMnO}_{4},{ }^{29}$
Luminol- $\mathrm{H}_{2} \mathrm{O}_{2}$-(Mn(III) DP, ${ }^{23}$ and graphene oxide (GO)-luminoldissolved oxygen (DO). ${ }^{30}$

Usually, the conventional experiment design (univariate optimization) is used as the method for optimizing the chemical systems. Through the typical experiment design, the first variable is changed and its effect is assessed and then, the same accomplishes for the second variable and so on. Unfortunately, this experiment design cannot always be used for every system and experiment. In some conditions in addition to the existence of a multivariable reaction, the interaction between the variables affects the reaction. ${ }^{31}$ Response surface methodology (RSM) is a collection of the effective mathematical and statistical techniques for optimizing, developing, and improving the processes. ${ }^{32}$ RSM not only quantifies the relationship between variables and obtained surface response but also estimates the linear and the quadratic effect of the factors. Moreover, RSM predicts the model (equation) for the response as well as it proposes the optimal value for each factor. ${ }^{33}$ Based on the selected design: central composite or Box-Behnken designs, various experimental data require. ${ }^{34}$ The central composite design (CCD), as a prevalent application of RSM, presents useful information with fewer tests rather than the full factorial design. ${ }^{35}$ Therefore, the implementation of chemometric systems has attracted a lot of attention in recent years. For example, central composite design (CCD) has been utilized for assessing the photocatalytic effect of dye solution on supported $\mathrm{TiO}_{2}$ nanoparticles, ${ }^{36}$ to monitor the biodegradation of lindane. ${ }^{37}$ Furthermore, CCD was used to modify the different conditions of the environmental process, ${ }^{38}$ manufacturing operation, ${ }^{39}$ and analytical applications. ${ }^{40,}{ }^{41}$ The purpose of this investigation is the presentation new, exact, and fast $\mathrm{CL}$ system based on using of $\mathrm{KMnO}_{4}$ as an oxidant in the presence of Rh.6G, SDS, and $\mathrm{H}_{2} \mathrm{SO}_{4}$ for measuring PCM and using CCD condition for optimizing the suggested procedure. The variables (factors) investigated for the optimization were the concentration of Rh.6G, $\mathrm{SDS}, \mathrm{H}_{2} \mathrm{SO}_{4}$, and $\mathrm{KMnO}_{4}$. The proposed $\mathrm{CL}$ system was employed for the determination of PCM in tablet, oral drop, and human urine 
samples by standard addition method and the satisfactory results were obtained.

\section{Experimental}

\section{Materials and reagents}

All experiments were done with chemicals of analytical reagentgrade. Furthermore, the double-distilled water was applied for preparing all the required solutions. Sodium dodecyl sulphate (SDS), cetyltrimethylammonium bromide (CTMAB), Triton X-100, rhodamine.6G (Rh.6G), Eu(III), formaldehyde, hydrochloric acid, sulphuric acid, phosphoric acid, and potassium permanganate were obtained from Merck (Darmstadt, Germany).

\section{Sample preparation}

For determining PCM in the tablets, ten commercial samples (pills) were gathered. In the first step, each commercial sample was measured by the scale (Shimadzu AW 320) for calculating the average weight. Then they were placed in the mortar for grinding to the fine mesh. The required amount of the powdered tablets dissolved and then, it extracted with the $25 \mathrm{~mL}$ water into the ultrasonic bath for $15 \mathrm{~min}$. The solution was filtered by filter paper and, its volume was made up to $50 \mathrm{~mL}$ with distilled water for obtaining a solution with a concentration of PCM $3.3 \mathrm{mM}$. For PCM oral drop, $0.25 \mathrm{~mL}$ of the oral drop was placed in the glass vessel, and then, the distilled water was added. In the next step, the solution was diluted to the volume with distilled water in the $50 \mathrm{~mL}$ calibration flask. For preparing PCM urine sample, $\mathrm{NaOH} 2 \mathrm{M}$ was added to the urine sample so that, $\mathrm{pH}$ of the urine sample increased to 9-10, then this solution was filtered. After that, $\mathrm{pH}$ of the solution was decreased to the neutral $\mathrm{pH}$ by adding $\mathrm{HCl} 2 \mathrm{M}$. Finally, by dissolving the $25 \mathrm{mg}$ pure $\mathrm{PCM}$ in the urine sample and diluting with the urine to $50 \mathrm{~mL}$, the solution gained with the PCM concentration $3.3 \mathrm{mM}$ in the urine.

\section{Instrumentaion and experimental}

In this investigation, Berthold model LB 9509 luminometer (Germany) was used. The CL spectra were obtained by a Hitachi F2500 spectrofluorimeter (Japan). CL intensity was assessed in the batch system by a $2 \mathrm{~mL}$ cell. In brief, $26 \mu \mathrm{L}$ of Rh.6G (0.1 M), $9.3 \mu \mathrm{L}$ of $\mathrm{H}_{2} \mathrm{SO}_{4}(1 \mathrm{M}), 780 \mu \mathrm{LSDS}(10 \%(\mathrm{w} / \mathrm{v}))$ were added to the cell with an appropriate volume of PCM samples, and the final volume reached to $2 \mathrm{~mL}$ with distilled water. After that, $184 \mu \mathrm{L}$ of $\mathrm{KMnO}_{4}(0.05 \mathrm{M})$ was injected by an automatic injector, and the $\mathrm{CL}$ signal was monitored versus time automatically. Maximum $\mathrm{CL}$ intensity was used as an analytical signal.

\section{Experimental design}

Generally, based on the 4-factor CCD experimental design, correlating the dependent and the independent variables are shown using a second-order equation (Eq. (1)).
$Y=b_{0}+b_{1} x_{1}+b_{2} x_{2}+b_{3} x_{3}+b_{4} x_{4}+b_{11} x_{1}^{2}+b_{22} x_{2}^{2}+b_{33} x_{3}^{2}+b_{44} x_{4}^{2}+$ $b_{12} x_{1} x_{2}+b_{13} x_{1} x_{3}+b_{14} x_{1} x_{4}+b_{23} x_{2} x_{3}+b_{24} x_{2} x_{4}+b_{34} x_{3} x_{4}(1)$

According to this equation, $\mathrm{Y}$ is the response variable of $\mathrm{CL}$ efficiency, $b_{0}$ is the constant of the second-order equation, $b_{i}$ is the regression coefficient of the linear effect, $b_{i i}$ presents the regression coefficient for the quadrate effect, $b_{i k}$ describes the regression coefficient for the interaction effect and $x_{i}$ is coded experimental range of the variables. ${ }^{36}$ According to the $C C D$ method, each variable was considered at the five levels, which showed with codes $(+\alpha,+1,0,-1$, $-\alpha) \cdot{ }^{37}$ The introductory experiments were performed to determine the minimum and maximum range of the variables (see Table $S 1^{\dagger}$ ). In the CCD method, the number of the experiments equals $2^{\mathrm{k}}+2 \mathrm{~K}+\mathrm{n}$ ( $K$ is the number of the parameter (variable) and $n=7$ based on 4factor CCD). ${ }^{31}$ The parameters studied for the optimization were the concentrations of $\mathrm{H}_{2} \mathrm{SO}_{4}, \mathrm{KMnO}_{4}, \mathrm{Rh} .6 \mathrm{G}$, and SDS so that the number of experiments was 31. Based on the concentration range (Table $\mathrm{S}^{\dagger}{ }^{\dagger}$ ), the 4-factor CCD matrix, experimental data (see ESI Table $\mathrm{S}^{\dagger}$ ) and, the analysis have been done by Minitab 17.1 .0 software $^{42}$, the second-order equation gained. This equation consists of the effective variables in the proposed CL system (Eq. (5)). Using the data Minitab 17.1.0 software, ${ }^{42}$ the optimization performed and, the optimal values of the effective parameters on the $\mathrm{CL}$ response obtained.

\section{Results and discussions}

\section{CL spectra}

The major aim of this research was the presentation of a novel $\mathrm{CL}$ system for detecting PCM. The presented mechanism was a proposal based on the $C L$ spectra, fluorescence emission (Fig. 1). With evaluating the $\mathrm{CL}$ spectra of the proposed method, the possible mechanism of this $C L$ reaction may be described. Fig. 1 shows the $C L$ spectrum of $\mathrm{PCM}^{-\mathrm{KMnO}_{4}}$ (A), the fluorescence spectrum of Rh.6G (B), and $\mathrm{CL}$ spectrum of the proposed $\mathrm{CL}$ reaction (C). The evaluation of the mechanism was out of the scope of this research; however, future investigations would explore the mechanism of this.

By comparing these spectra, it could be seen that the maximum $\mathrm{CL}$ emission of the proposed reaction had a similar characteristic emission spectra with the fluorescence spectra of Rh.6G. They were both located at approximately $560 \mathrm{~nm} .{ }^{43}$ Therefore, the proposed CL reaction was attributable to the excited-state Rh.6G. The incorporation of SDS in this system was not a new luminophore. Therefore, the enhanced $\mathrm{CL}$ intensity can be referred mainly to the catalysis effect of SDS.$^{44}$ The mechanism for this emission is most likely due to the following reaction mechanisms (Eq. (2 to 4)):






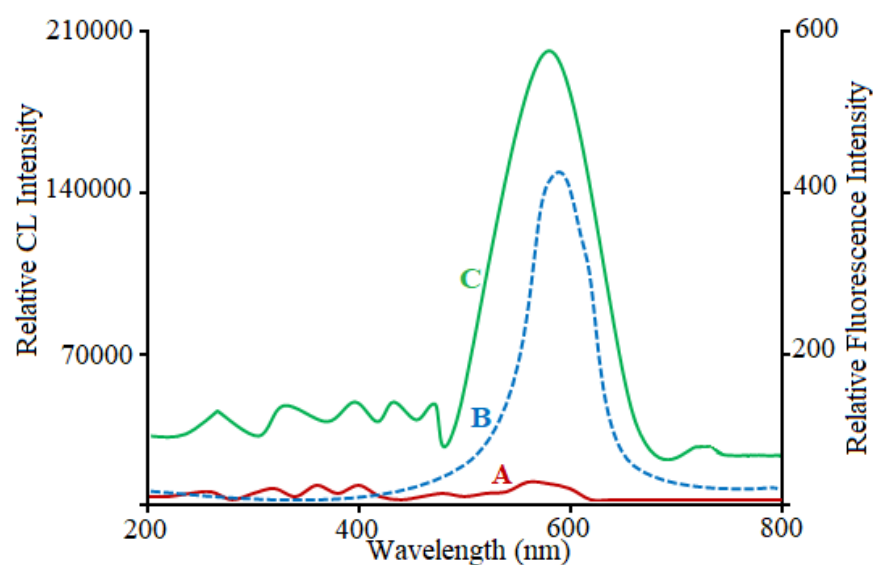

Fig. 1 The spectra distribution of (A) $\mathrm{CL}$ of $\mathrm{PCM}-\mathrm{KMnO}_{4}$, (B) fluorescence emission of Rh.6G excited at $365 \mathrm{~nm}$, (C) CL emission of proposed $\mathrm{CL}$ system. Condition: $\mathrm{KMnO}_{4}$, $4.6 \mathrm{mM}$; Rh.6G, $1.3 \mathrm{mM}$; SDS, $3.9 \%(\mathrm{w} / \mathrm{v})$; $\mathrm{H}_{2} \mathrm{SO}_{4}, 9.3 \mathrm{mM}$; and PCM, $6.6 \mu \mathrm{M}$. All of the reagents dissolved in distilled water.

\section{Kinetic study}

The kinetic effects of Rh.6G, SDS, $\mathrm{H}_{2} \mathrm{SO}_{4}$ were studied on PCM-KMnO 4 $\mathrm{CL}$ system (as shown in Fig. 2). The oxidation of $\mathrm{PCM}$ by $\mathrm{KMnO}_{4}$ generates ultra-weak $\mathrm{CL}$ intensity (curve $\mathrm{A}$ ). Moreover, the effects of $\mathrm{H}_{2} \mathrm{SO}_{4}$ (curve $\mathrm{B}$ ), SDS (curve $\mathrm{C}$ ), Rh6G (curve D), and all of the reagents, including Rh.6G, SDS, and $\mathrm{H}_{2} \mathrm{SO}_{4}$ (curve E) were investigated on $\mathrm{CL}$ signal of $\mathrm{PCM}-\mathrm{KMnO}_{4}$ reaction. The $\mathrm{H}_{2} \mathrm{SO}_{4}$ (curve $B$ ) and SDS (curve $C$ ) had inconsiderable effects on the $C L$ signal. The Rh.6G (curve $\mathrm{D}$ ) increased the $\mathrm{CL}$ signal of the $\mathrm{PCM}-\mathrm{KMnO}_{4}$ reaction significantly. Based on the results, Rh.6G-SDS- $\mathrm{H}_{2} \mathrm{SO}_{4}$ (curve E) was found to have the most increase in $\mathrm{CL}$ signal of $\mathrm{PCM}-\mathrm{KMnO}_{4}$ reaction.



Fig. 2 The kinetic curves of (A) $\mathrm{KMnO}_{4}-\mathrm{PCM}$ (B) $\mathrm{KMnO}_{4}-\mathrm{PCM}-\mathrm{H}_{2} \mathrm{SO}_{4}(\mathrm{C})$ $\mathrm{KMnO}_{4}$-PCM-SDS (D) $\mathrm{KMnO}_{4}$-PCM-Rh.6G (E) KMnO${ }_{4}-\mathrm{PCM}-\mathrm{H}_{2} \mathrm{SO}_{4}$-SDSRh.6G system. Condition: $\mathrm{KMnO}_{4}, 4.6$ mM; Rh.6G, 1.3 mM; SDS, $3.9 \%$ $(\mathrm{w} / \mathrm{v}) ; \mathrm{H}_{2} \mathrm{SO}_{4}, 9.3 \mathrm{mM}$; and PCM, $0.9 \mu \mathrm{M}$. All of the reagents dissolved in distilled water.

\section{Selection of enhancer}

$\mathrm{KMnO}_{4}$ is a strong oxidizing agent, soluble in water, inexpensive and, nontoxic reagent so that, it has different applications not only in the chemistry but also in industry, ${ }^{45}$ agriculture, ${ }^{46}$ and, medicine. ${ }^{47}$ Therefore, we decided to test another enhancer for determining the PCM based on $\mathrm{KMnO}_{4}$ (as an oxidant) with low LOD, wide linear range, fast response, simple procedure, and economic advantages. $\mathrm{KMnO}_{4}-\mathrm{PCM}$ shows a so weak $\mathrm{CL}$ emission, as seen in Fig. 3 (spectra A), as expected from previous results. ${ }^{29}$ Therefore, to enhance $\mathrm{CL}$ intensity, various compounds such as Rh.6G, Eu(III), and formaldehyde were examined as the potential enhancer. The results showed that Rh.6G had the most apparent enhancement (Fig. 3) so that, Rh.6G was selected as the $\mathrm{CL}$ enhancer of $\mathrm{PCM}-\mathrm{KMnO}_{4}$ reaction.



Fig. $3 \mathrm{CL}$ spectrum of (A) $\mathrm{KMnO}_{4}-\mathrm{PCM} \mathrm{CL}$ system, (B) $\mathrm{KMnO}_{4}-\mathrm{PCM}$ in the presence of $\mathrm{Eu}(\mathrm{III}),(\mathrm{C}) \mathrm{KMnO}_{4}-\mathrm{PCM}$ in the presence of formaldehyde, (D) $\mathrm{KMnO}_{4}-\mathrm{PCM}$ in the presence of Rh.6G. Condition: $\mathrm{KMnO}_{4}, 2.5 \mathrm{mM}$; $\mathrm{PCM}$, $6.6 \mu \mathrm{M}$, enhancer (Rh.6G, formaldehyde, and $\mathrm{Eu}(\mathrm{III})$ ), $1 \mathrm{mM}$. All of the reagents dissolved in distilled water.

\section{Selection of surfactant}

Incorporation of a surfactant within the organized assembly can result in the enhancement of $\mathrm{CL}$ responses, thereby improving the sensitivity of the $\mathrm{CL}$ system. ${ }^{48}$ This enhancement is achieved by either an increase in the quantum efficiency of $\mathrm{CL}$ or the energy-transfer efficiency in the $\mathrm{CL}$ reactions between the reagents and the enhancers involved in the $\mathrm{CL}$ reaction, which are insoluble in water. ${ }^{49}$ In this study, after selecting Rh.6G as $\mathrm{CL}$ enhancer, we decided to investigate the effect of surfactant on the CL oxidation of PCM using the following surfactant: a non-ionic surfactant (Triton X-100), a cationic surfactant (CTMAB), and an anionic surfactant (SDS) at a concentration of $5 \%(\mathrm{w} / \mathrm{v})$. As expected, the combination of both the surfactant and sensitizer has an impact of the $\mathrm{CL}$ observed. The largest enhancement was from the combination of SDS and Rh.6G (see Fig. 4). This was therefore taken forward for the rest of that analysis.

The difference between the $\mathrm{CL}$ intensities and emission wavelengths in the different surfactants related to the character of each surfactant. Micelles may be implemented to improve the $\mathrm{CL}$ measurement by the change in the microenvironment (i.e. polarity, viscosity, acidity, etc.), solubilization and, electrostatic effects. Based on the oxidation mechanism of paracetamol, ${ }^{50}$ SDS as an anionic surfactant decreases the accumulation of positive charge on the intermediate of oxidation of PCM (decrease in the electrostatic effect). Then, the oxidation reaction runs fast and efficiently 
(increase in energy transfer efficiency in the $\mathrm{CL}$ reaction between reagents and $C L$ enhancer).

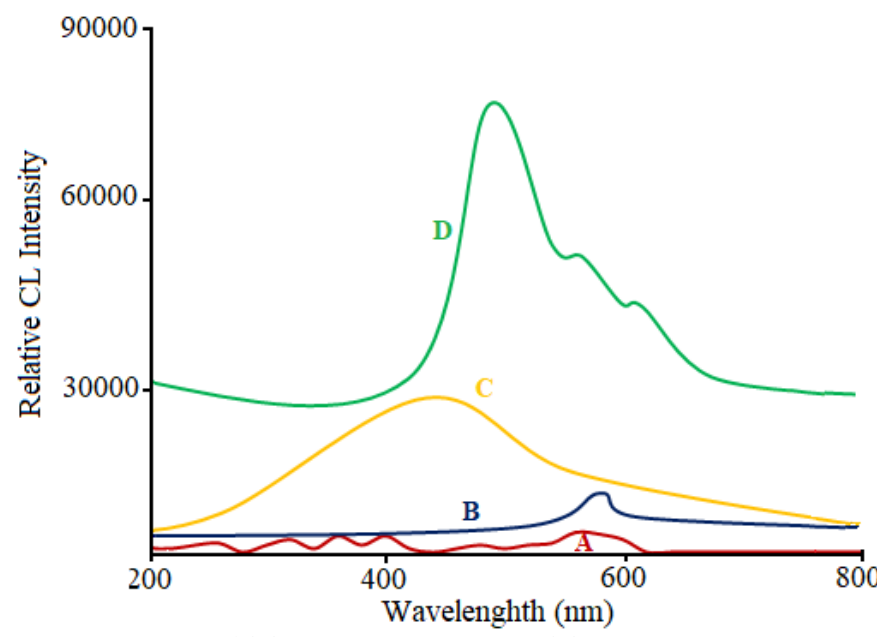

Fig. 4 spectra $\mathrm{CL}$ of (A) $\mathrm{KMnO}_{4}-\mathrm{PCM}$ reaction, (B) $\mathrm{KMnO}_{4}-\mathrm{PCM}-\mathrm{Rh}$.6G in the presence of triton $\mathrm{X}-100$, (C) $\mathrm{KMnO}_{4}-\mathrm{PCM}-\mathrm{Rh} .6 \mathrm{G}$ in the presence of CTMAB, (D) $\mathrm{KMnO}_{4}-\mathrm{PCM}-\mathrm{Rh} .6 \mathrm{G}$ in the presence of SDS. Condition: $\mathrm{KMnO}_{4}$, $2.5 \mathrm{mM}$; Rh.6G, $1 \mathrm{mM}$; PCM, 6.6 $\mu \mathrm{M}$ and surfactant (triton X-100, C TMAB and SDS), $5 \%(w / v)$. All of the reagents dissolved in distilled water.

\section{Selection of acid medium}

In this study, several acids, such as: $\mathrm{HCl}, \mathrm{H}_{3} \mathrm{PO}_{4}$, and $\mathrm{H}_{2} \mathrm{SO}_{4}$ were used in the $\mathrm{CL}$ system for detecting PCM. The experimental results of $\mathrm{CL}$ intensity for different applied acids were presented in ESI Fig. $\mathrm{S}^{\dagger}$. The results were selected based upon the difference between the analytical signal (all of the reagents in the presence of PCM) and background signal (all of the reagents without PCM). This can dramatically improve the signal-to-noise $(\mathrm{S} / \mathrm{N})$ ratio, having a positive influence on the sensitivity of the system. ${ }^{51} \mathrm{From} \mathrm{Fig.} \mathrm{S}^{\dagger}$, it was clear that $\mathrm{H}_{2} \mathrm{SO}_{4}$ gives the greatest $\mathrm{S} / \mathrm{N}$ ratio. Therefore, $\mathrm{H}_{2} \mathrm{SO}_{4}$ was selected for the following studies.

\section{Optimization}

$\mathrm{CL}$ is a highly sensitive technique, ${ }^{52}$ and in this study, the $\mathrm{CL}$ intensity is influenced by different variables (parameters) consist of the concentrations of $\mathrm{H}_{2} \mathrm{SO}_{4}, \mathrm{KMnO}_{4}, \mathrm{Rh} .6 \mathrm{G}$, and SDS. Therefore, it is important to determine the optimization value of these parameters. For optimizing the entire system, the central composite design (CCD) was utilized. In the first step of the optimization, some preliminary experiments have been tested, which were necessary for finding the concentration range of each parameter presented in ESI table $\mathrm{S}^{\dagger}$. The 4-factor CCD matrix and experimental data were reported in ESI Table $\mathrm{S}^{\dagger}$. In this design 31 runs were accomplished in the randomized arrangement to decrease the effect of the uncontrolled parameter on the response. Based on the result of the Table $\mathrm{S}^{\dagger}$ (see ESI for details), an empirical relationship between the response and variables was obtained and stated by following second-order equation (Eq. (5)). CL intensity efficiencies have been predicted by Eq. (5). The results indicate promising agreement between the experimental and predicted values of $C L$ efficiency with $R^{2}=0.9978$. For a model with proper-fitting of data $R^{2}$ should be closer to 1 and at least $0.8 .^{53}$ Also, $R^{2}$ increased by adding the other parameters to the model, even if the fluctuation of these parameters do not affect the system. ${ }^{54}$ Therefore, it was better to use the adjusted $R^{2}$ (Adj- $R^{2}$ ) to assess model adequacy. Adjusted $R^{2}$ was modified for the models (size or number of parameters). Indeed, when the added factors to the model were insignificant, the adjusted $R^{2}$ value decreased. ${ }^{54,55}$ In this study, Adj- $R^{2}$ value $(0.9958)$ is so close to $R^{2}$ value. The predicted $R^{2}(98.85 \%)$ implies that the model would be expected to explain about $98.85 \%$ of the variability in the new data (predicted value).

$y=84300-3738.9 X_{1}+2274.6 X_{2}-5426 X_{3}-5719.8 X_{4}-7650.1 X_{1}^{2}-$

$14848.5 X_{2}^{2}-8997.4 X_{3}^{2}-12761 X_{4}^{2}-2254.9 X_{1} X_{2}-803.7 X_{1} X_{3}-$

$5266.9 X_{1} X_{4}-1242.6 X_{2} X_{4}-4263.6 X_{3} X_{4}(5)$

$\mathrm{X}_{1}: \mathrm{H}_{2} \mathrm{SO}_{4} \quad \mathrm{X}_{3}: \mathrm{KMnO}_{4}$

$\mathrm{X}_{2}$ : SDS $\quad \mathrm{X}_{4}$ : Rh.6G

Analysis of variance (ANOVA) was done to determine whether the factors were statically significant. The results of ANOVA for the response value are shown in Table $\mathrm{S}^{\dagger}{ }^{\dagger}$, including the data related to mean square, $p$-value, F-value, degree of freedom (DOF), regression coefficients, and the sum of square. The $p$-value is the probability of applying value to determine its effect in the model based on the significant statically. ${ }^{56}$ The more significant corresponding coefficient has a smaller p-value. ${ }^{54}$ In the 95 confidence level, for the significant effect, the $p$-value should be equal or less than $0.05 .54,57$ Based on obtained $\mathrm{p}$-value in the ESI Table $\mathrm{S3}^{\dagger}$, all of the variables and their interaction were significant apart from the interaction between SDS and Rh.6G. This result could be related to $p$-value of the interaction between SDS and Rh.6G ( $p=0.308)$, while in the confidence level 95\%, factors with $p$-value $\leq 0.05$ were significant. In a model F-value was defined as the ratio between its residual error and mean square. ${ }^{36}$ Moreover, in a model at the level of significance, $\alpha$, a good prediction of experimental results happens if F-value is more than the tabulated value of F-distribution. In this study, F-value was obtained 508.03 . It is obviously that 508.03 is greater than tabulated $F(2.53$ at $95 \%$ confidence level) which verifies the adequacy of the model fits. The additional information about ANOVA was reported in ESI Table $\mathrm{S}^{\dagger}{ }^{\dagger}$.

\section{Effect of the variables as response surface}

The response surface plot and the contour plot were presented in ESI Fig. $\mathrm{S}^{\dagger}(\mathrm{A}-\mathrm{F})$ for illustrating the experimental factor, their interaction, and the quadratic factor effect on the response factor. Briefly, in the response surface and contour plot, two factors are simultaneously variable, while the other two factors are constant. Based on Fig. $\mathrm{S}^{\dagger}$, there is a certain range of each variable that in these ranges, response of $\mathrm{CL}$ intensity is greatest. For example, as shown in Fig. $\mathrm{S}^{\dagger}(\mathrm{A})$, the response is given as a function of $\mathrm{KMnO}_{4}$ and Rh.6G concentration and maintaining $\mathrm{H}_{2} \mathrm{SO}_{4}$ and SDS concentration at the fixed value. It indicates that high $\mathrm{CL}$ intensity could be achieved when $\mathrm{KMnO}_{4}$ concentration was in the range of 3.5 to $5.6 \mathrm{mM}$. CL intensity was declined over this range of $\mathrm{KMnO}_{4}$ due to absorb the emitted light by $\mathrm{KMnO}_{4} .{ }^{58}$ Moreover, to maximize the response, Rh.6G concentration was in the range from $1 \mathrm{mM}$ to 1.7 $\mathrm{mM}$. Based on the results, the intensity of $\mathrm{CL}$ at the higher 
concentrations of Rh.6G diminished. The reason of this reduction can be explained by the self-absorption of the $\mathrm{CL}$ emission by Rh.6G. ${ }^{59}$ This optimization process attempted to find the optimal experimental condition that provides maximum $\mathrm{CL}$ intensity. Finally, the optimum condition for the proposed $\mathrm{CL}$ system was $\mathrm{H}_{2} \mathrm{SO}_{4}, 9.3$ $\mathrm{mM}$; Rh.6G, $1.3 \mathrm{mM}$; SDS, 3.9\% w/v; and $\mathrm{KMnO}_{4}, 4.6 \mathrm{mM}$.

\section{Comparing the optimal value of $C C D$ and univariate optimization} method

For comparing the optimal value of each reagent based on the CCD condition and the classic optimization method (i.e. univariate), Table 1 was presented. Besides, in ESI Fig. $\mathrm{S3}^{\dagger}$ (A-D) shows the process of the optimization based on the classic optimization method so that the optimal value of each reagent was: $\mathrm{H}_{2} \mathrm{SO}_{4}, 0.02 \mathrm{M}$; Rh.6G, $2 \mathrm{mM}$; $\mathrm{SDS}, 4 \% \mathrm{w} / \mathrm{v}$; and $\mathrm{KMnO}_{4}, 5 \mathrm{mM}$.

Table 1 Comparing the optimal values of CCD condition and the univariate optimization method.

\begin{tabular}{ccccc}
\hline & \multicolumn{4}{c}{ Optimal value } \\
\cline { 2 - 5 } $\begin{array}{c}\text { Optimization } \\
\text { method }\end{array}$ & $\mathrm{H}_{2} \mathrm{SO}_{4}(\mathrm{M})$ & $\mathrm{SDS} \%$ & $\mathrm{KMnO}_{4}(\mathrm{mM})$ & $\mathrm{Rh} .6 \mathrm{G}(\mathrm{mM})$ \\
\hline $\mathrm{CCD}$ & 0.0093 & 3.9 & 4.6 & 1.3 \\
univariate & 0.02 & 4 & 5 & 2
\end{tabular}

\section{Interference studies}

For evaluating the concentration of PCM in biological matrices, it is vitally important to ensure that the overdoses are diagnosed rapidly. However, as with any point-of-care system, a non-invasive approach is always preferred. Therefore, we have highlighted the utility of our $\mathrm{CL}$ system by monitoring the [PCM] in human urine. Human urine often presents a problem for analytical measurement due to its composition which consists of various compounds (about 3000 compounds) including metabolic products, bacterial products as well as compounds from an individual diet, cosmetic use, and the local environment. The concentration of these compounds is so low so that they have been reported as $\mu \mathrm{M} / \mathrm{mM} .^{60}$ To evaluate the potential of a number of key interferences, we examined their impact on our $\mathrm{CL}$ system, the results of which are illustrated in Table 2. Moreover, we investigated the effect of the existence of some common recipients used in drugs (including starch, codeine, caffeine, sodium saccharin) ${ }^{61}$ and EDTA (as a high usage organic compound in medical $)^{62}$ in the proposed $\mathrm{CL}$ method. The interference of foreign substances was assessed by analyzing a standard solution of PCM at a concentration of $33 \mu \mathrm{M}$. The tolerance limit was taken as the highest concentration of foreign substances, which cause an approximate $\pm 5 \%$ relative error in the assessment.

Table 2 The tolerance of the different substances in PCM determination.

\begin{tabular}{cc}
\hline Substance & Concentration ratio PCM \\
\hline $\mathrm{Ca}^{2+}, \mathrm{Mg}^{2+}, \mathrm{Co}^{2+}, \mathrm{Ni}^{2+}, \mathrm{Ca}^{2+}, \mathrm{Cu}^{2+}$, & \\
$\mathrm{Mn}^{2+}, \mathrm{Al}^{3+}, \mathrm{Ba}^{2+}, \mathrm{Sr}^{2+}, \mathrm{Cr}^{2+}, \mathrm{Zn}^{2+}$, & $\geq 1500$ \\
$\mathrm{Cr}^{3+}, \mathrm{PO}_{4}{ }^{3-}, \mathrm{NO}_{3}{ }^{-}, \mathrm{Na}^{+}, \mathrm{K}^{+}, \mathrm{Cl}^{-}$ &
\end{tabular}

\section{Analytical Performance}

The impact of PCM concentration on the $\mathrm{CL}$ response was investigated across a concentration range from $6.6 \mathrm{nM}$ to $0.198 \mathrm{mM}$ (Fig. 5). The intensities of $\mathrm{CL}$ emission versus PCM concentration were applied for the calibration curve. Under the selected system, the relative intensity of $\mathrm{CL}$ was linear over the range of $\mathrm{PCM} 0.12 \mu \mathrm{M}$ to $0.185 \mathrm{mM}$. The regression equation was $\Delta \mathrm{l}=12768 \mathrm{X}+122787$ ( $\mathrm{X}$ is the concentration of PCM), with a correlation coefficient of 0.9989 $(n=5)$. The detection limit $(3 \sigma)$ for PCM was $7.8 \times 10^{-8} \mathrm{M}$. The relative standard deviation (RSD) was $0.81 \%$ for the 5 determination of 13.2 $\mu \mathrm{M}$ PCM.

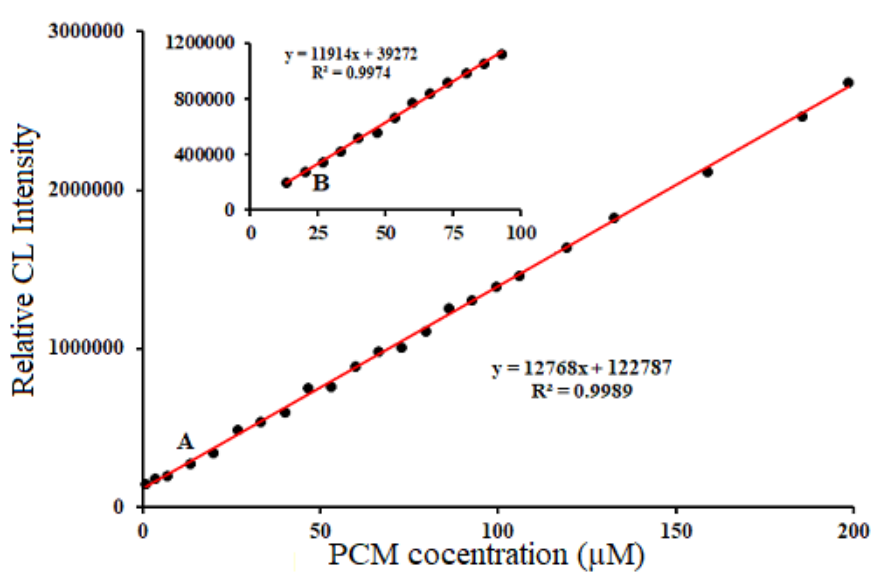

Fig. 5 (A) The calibration curve for the detection of PCM based on CCD method; Condition: $\mathrm{KMnO}_{4}$, $4.6 \mathrm{mM}$; Rh.6G, $1.3 \mathrm{mM}$; SDS, $3.9 \%(\mathrm{w} / \mathrm{v})$; $\mathrm{H}_{2} \mathrm{SO}_{4}, 9.3 \mathrm{mM}$; (B) The calibration curve for the detection of PCM based on univariate optimization method; Condition: $\mathrm{KMnO}_{4}, 5 \mathrm{mM}$; Rh.6G, 2 $\mathrm{mM} ; \mathrm{SDS}, 4 \%(\mathrm{w} / \mathrm{v}) ; \mathrm{H}_{2} \mathrm{SO}_{4}, 0.02 \mathrm{M}$.

We also reported the calibration curve based on the univariate optimization method (Fig. 5 B). By comparing the analytical parameters (i.e. linear range, LOD, and RSD \%) of presented $\mathrm{CL}$ reaction based on two different optimization methods, it could be found that optimization based on CCD method was more acceptable (seeTable 3). Therefore, CCD condition not only was a fast method with fewer tests for optimizing but also it had a proper and satisfactory analytical parameter rather than a univariate optimization method.

Table 3 The result of detecting PCM based on CCD and univariate optimization method.

\begin{tabular}{lccc}
\hline Method & $\begin{array}{c}\text { Linear dynamic range } \\
(\mu \mathrm{M})\end{array}$ & RSD\% & LOD (M) \\
\hline CCD & $0.12 \mu \mathrm{M}-0.185 \mathrm{mM}$ & $0.81 \%$ & $7.8 \times 10^{-8}$
\end{tabular}


For easy comparison, analytical parameters of the proposed $\mathrm{CL}$ method for the determination of PCM and some other analytical methods, Table 4 is presented. According to table 4, the proposed method has an analytical parameter comparable to a number of the prior methods and inferior to some other methods. It should be stated that the proposed method not only has some advantages like acceptable LOD and proper linear dynamic range but also has compatibility with both chemical and biological matrices. Moreover, easy preparations, simple, and rapid analysis, as well as utilizing inexpensive reagents. Also, $\mathrm{CL}$ method is a simple and uncomplicated method utilizing a low-cost device.

Table 4 Analytical parameters of the methods developed for the determination of PCM.

\begin{tabular}{|c|c|c|c|c|c|}
\hline Method & LOD (M) & $\begin{array}{l}\text { Linear dynamic } \\
\text { range (M) }\end{array}$ & $\begin{array}{c}\text { RSD } \\
\%\end{array}$ & Sample & Ref. \\
\hline Amperometriy & $1.1 \times 10^{-7}$ & $10^{-4}-10^{-6}$ & - & Tablet & 9 \\
\hline $\begin{array}{l}\text { Electrochemical } \\
\text { sensor }\end{array}$ & $1.2 \times 10^{-8}$ & $4 \times 10^{-8}-8 \times 10^{-4}$ & - & $\begin{array}{l}\text { Human } \\
\text { serum }\end{array}$ & 10 \\
\hline $\begin{array}{l}\text { Differential pulse } \\
\text { voltammetry }\end{array}$ & $5.36 \times 10^{-8}$ & $5 \times 10^{-7}-1 \times 10^{-4}$ & - & $\begin{array}{l}\text { Tablet, } \\
\text { Urine, } \\
\text { Saliva }\end{array}$ & 11 \\
\hline $\begin{array}{l}\text { Square wave } \\
\text { voltammetry }\end{array}$ & $5.3 \times 10^{-8}$ & $2.8 \times 10^{-6}-1.9 \times 10^{-5}$ & & Urine & 12 \\
\hline $\begin{array}{c}\text { Spectrophotomet } \\
\text { ry }\end{array}$ & $9.8 \times 10^{-8}$ & $3.3 \times 10^{-7}-5.3 \times 10^{-6}$ & 3.3 & $\begin{array}{l}\text { Tablet, } \\
\text { Urine }\end{array}$ & 16 \\
\hline $\begin{array}{l}\text { FIA-Multiple } \\
\text { pulse } \\
\text { amperometry }\end{array}$ & $3 \times 10^{-8}$ & $8 \times 10^{-8}-1 \times 10^{-4}$ & - & $\begin{array}{c}\text { Tablet, } \\
\text { Urine, } \\
\text { Human } \\
\text { serum }\end{array}$ & 18 \\
\hline $\begin{array}{c}\mathrm{FI}-\mathrm{CL} \\
\text { (luminol- } \mathrm{KMnO}_{4} \text { ) }\end{array}$ & $1 \times 10^{-8}$ & $2.5 \times 10^{-8}-2.5 \times 10^{-7}$ & 2.3 & Tablet & 17 \\
\hline $\begin{array}{l}\text { Reverse phase } \\
\text { capillary liquid } \\
\text { chromatography }\end{array}$ & $5.9 \times 10^{-7}$ & $2.4 \times 10^{-4}-9.5 \times 10^{-4}$ & 2.32 & Tablet & 19 \\
\hline LC-MS/MS & $6.6 \times 10^{-9}$ & $6.6 \times 10^{-6}-3.3 \times 10^{-3}$ & - & $\begin{array}{l}\text { Pure } \\
\text { form }\end{array}$ & 20 \\
\hline RP-HPLC & $1.4 \times 10^{-6}$ & $6.6 \times 10^{-5}-3.9 \times 10^{-4}$ & 0.49 & Tablet & 21 \\
\hline $\begin{array}{c}\text { Capillary } \\
\text { electrophoresis }\end{array}$ & $1.6 \times 10^{-6}$ & $1 \times 10^{-4}-15 \times 10^{-3}$ & $<5.2$ & Tablet & 22 \\
\hline $\begin{array}{l}\mathrm{FI}-\mathrm{CL} \text { (luminol- } \\
\mathrm{H}_{2} \mathrm{O}_{2}-\mathrm{Fe}(\mathrm{CN})_{6}^{3-)}\end{array}$ & $1.4 \times 10^{-5}$ & $1.6 \times 10^{-5}-8.3 \times 10^{-5}$ & 2.2 & Tablet & 28 \\
\hline $\mathrm{CL}(\mathrm{PCM}-\mathrm{Ce}(\mathrm{IV}))$ & - & $6.6 \times 10^{-6}-6.6 \times 10^{-5}$ & 2.2 & Tablet & 63 \\
\hline $\begin{array}{l}\mathrm{FI}-\mathrm{CL} \text { (tris }(2,2,- \\
\text { bipyridyl) } \\
\text { ruthenium (II) - } \\
\mathrm{KMnO}_{4} \text { ) }\end{array}$ & $1.3 \times 10^{-6}$ & $2 \times 10^{-6}-3.3 \times 10^{-4}$ & 1.1 & Tablet & 29 \\
\hline $\begin{array}{l}\mathrm{CL} \text { (luminol- } \mathrm{H}_{2} \mathrm{O}_{2-} \\
\text { (Mn(III) DP) }\end{array}$ & $1.8 \times 10^{-9}$ & $6.6 \times 10^{-9}-6.6 \times 10^{-7}$ & 2.7 & Tablet & 23 \\
\hline $\begin{array}{c}\text { CL (graphene } \\
\text { oxide (GO)- } \\
\text { luminol- dissolved } \\
\text { oxygen (DO)) }\end{array}$ & $7.9 \times 10^{-8}$ & $1 \times 10^{-7}-1 \times 10^{-4}$ & 3.38 & Tablet & 30 \\
\hline This study & $7.8 \times 10^{-8}$ & $1.2 \times 10^{-7}-1.85 \times 10^{-4}$ & 0.81 & $\begin{array}{l}\text { Tablet, } \\
\text { Drop, } \\
\text { Urine }\end{array}$ & - \\
\hline
\end{tabular}

\section{Sample analysis}

According to the detailed procedure mentioned in the experimental section, the standard addition method was used for measuring PCM in pharmaceutical (tablets, oral drop) and human urine spiked samples. The results listed in Table 5 shows the added and detected concentrations of PCM for all investigated samples. Recovery value was obtained for spiked samples from 95.5 to $105.7 \%$. The results show a satisfactory determination of PCM without significant matrix effects. The presented method is promising due to some advantages such as lower LOD compared to available studies in the literature, ${ }^{9}$,

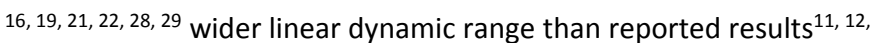
63 and employing the samples containing diverse matrix effect compared to available studies. 10, 17, 20, 30 Furthermore, this investigation is rapid, simple, and cheaper compared to methods reported in the literature. ${ }^{18,30}$

Table 5 Determination of PCM in the pharmaceutical formulation and biological urine samples using the $\mathrm{KMnO}_{4}-\mathrm{Rh} .6 \mathrm{G}$ - SDS in the presence of $\mathrm{H}_{2} \mathrm{SO}_{4} \mathrm{CL}$ system ( $\mathrm{n}=3$ ). Condition: $\mathrm{KMnO}_{4}$, $4.6 \mathrm{mM}$; Rh.6G, $1.3 \mathrm{mM}$; SDS, 3.9\% $(\mathrm{w} / \mathrm{v}) ; \mathrm{H}_{2} \mathrm{SO}_{4}, 9.3 \mathrm{mM}$. All of the reagents dissolved in distilled water.

\begin{tabular}{|c|c|c|c|c|}
\hline Samples & & Added $(\mu \mathrm{M})$ & Found $(\mu \mathrm{M})$ & Recovery \% \\
\hline \multirow[t]{6}{*}{ Tablets } & $A^{\S}$ & 50 & $50.4 \pm 0.026$ & 100.8 \\
\hline & & 80 & $76.4 \pm 0.021$ & 95.5 \\
\hline & $\mathrm{B}^{\S \S}$ & 50 & $51.8 \pm 0.035$ & 103.6 \\
\hline & & 80 & $78.3 \pm 0.029$ & 97.9 \\
\hline & $C^{\S \S \S}$ & 80 & $82.6 \pm 0.018$ & 103.2 \\
\hline & & 100 & $98.8 \pm 0.086$ & 98.8 \\
\hline \multirow[t]{2}{*}{ PCM drop } & & 30 & $31.7 \pm 0.043$ & 105.7 \\
\hline & & 60 & $59.1 \pm 0.057$ & 98.5 \\
\hline \multirow[t]{2}{*}{ Urine } & & 10 & $9.6 \pm 0.033$ & 96 \\
\hline & & 100 & $97.7 \pm 0.013$ & 97.7 \\
\hline \multicolumn{5}{|c|}{ Paracetamol 325 mg (Ariya daru Co) } \\
\hline \multicolumn{5}{|c|}{ Paracetamol 500mg (Alborz daru Co) } \\
\hline Paracetam & & (Alhavi Co) & & \\
\hline
\end{tabular}

\section{Conclusions}

In this study, the new CL system was presented for determining PCM. Moreover, the central composite design applies instead of the conventional method based on the satisfactory presented analytical parameters (see Table 4). Besides, in CCD, the interaction effect of variables influence in the experiment, this method is fast, consumes low reagents, and it can be carried out by less number of the experiment. The results of this study indicate that $\mathrm{CL}$ system of Rh.6G-KMnO${ }_{4}-\mathrm{H}_{2} \mathrm{SO}_{4}$-SDS for the determination of PCM has high sensitivity, accuracy, and provides a low detection limit. This method is simple and does not require any pre-treatment process, rapid and cheap, while the sensitivity is comparable with other systems and methods. The proposed CL system has satisfactory selectivity. For example, Ascorbic acid is a major interference during the determination of PCM at the physical solution and some pharmaceutical preparation. ${ }^{64}$ Based on our investigation, the detection of PCM in the presence of Ascorbic acid at the mentioned range of the interference was possible. The presented method was successfully used in the determination of PCM in a different matrix of pharmaceutical preparation and a biological sample of urine using the standard addition method. Also, the results showed that the CCD method is suitable for the optimization of the effective factors on the $\mathrm{CL}$ reaction.

\section{Conflicts of interest}

There are no conflicts to declare. 


\section{Acknowledgements}

We thank the University of Tabriz for financial support.

\section{Supporting Information}

For more investigation of the details of this study, some figures and tables are reported in the supporting information that it includes:

Table S1 The concentrate rang of each parameter in 5 levels based on $\operatorname{CCD}(n=2)$

Table S2 Design matrixes generated for CCD

Table S3 ANOVA

Fig. S1 Effect of the various acids on the signal/blank ratio

Fig. S2 Response surface plot and contour plot of CL intensity

Fig. S3 univariate optimization

\section{References}

J. Martinez Calatayud and C. Gomez Benito, Analytica Chimica Acta, 1990, 231, 259-264.

K. Parfitt, Martindale: the complete drug reference, Pharmaceutical press, United Kingdom, 2017.

J. Vale and A. Proudfoot, The Lancet, 1995, 346, 547-552. M. d. I. A. Oliva, R. A. Olsina and A. N. Masi, Talanta, 2005, 66, 229-235.

A. Jimenez and M. Navas, Grasas y Aceites, 2002, 53, 64 75.

L. Deng, J. Zhai and X. Xie, Analytical chemistry, 2019, 91 , 8638-8643.

M. E. Bosch, A. R. Sánchez, F. S. Rojas and C. B. Ojeda, Journal of pharmaceutical and biomedical analysis, 2006, 42, 291-321.

X. Liu, W. Na, H. Liu and X. Su, Biosensors and Bioelectronics, 2017, 98, 222-226.

M. S. Quintino, K. Araki, H. E. Toma and L. Angnes, Electroanalysis: An International Journal Devoted to Fundamental and Practical Aspects of Electroanalysis, 2002, 14, 1629-1634.

S. J. Saleem and M. Guler, Electroanalysis, 2019, 31, 2187 2198.

J. R. Camargo, I. A. Andreotti, C. Kalinke, J. M. Henrique, J. A. Bonacin and B. C. Janegitz, Talanta, 2020, 208, 120458. M. Baccarin, F. A. Santos, F. C. Vicentini, V. Zucolotto, B. C. Janegitz and O. Fatibello-Filho, Journal of Electroanalytical Chemistry, 2017, 799, 436-443.

K. Ghanbari and S. Bonyadi, New Journal of Chemistry, 2018, 42, 8512-8523.

H. Filik, M. Hayvali and E. Kilic, Analytica chimica acta 2005, 535, 177-182.

Z. Bouhsain, S. Garrigues and M. de La Guardia, Analyst, 1996, 121, 635-639.

B. Doğan, A. Elik and N. Altunay, Microchemical Journal 2020, 104645.

D. Easwaramoorthy, Y.-C. Yu and H.-J. Huang, Analytica chimica acta, 2001, 439, 95-100.
20

A. M. Santos, T. A. Silva, F. C. Vicentini and O. FatibelloFilho, Arabian Journal of Chemistry, 2020, 13, 335-345.

M. E. Salih, A. Aqel, B. Y. Abdulkhair, Z. A. Alothman, M. A. Abdulaziz and A. Y. Badjah-Hadj-Ahmed, Journal of chromatographic science, 2018, 56, 819-827.

S. A. Boltia, A. T. Soudi, E. S. Elzanfaly and H. E. Zaazaa, Journal of Chromatographic Science, 2019.

E. A. Abdelaleem, I. A. Naguib, E. S. Hassan and N. W. Ali, Journal of pharmaceutical and biomedical analysis, 2015, 114, $22-27$.

R. R. Cunha, M. M. Ribeiro, R. A. Muñoz and E. M. Richter, Journal of separation science, 2017, 40, 1815-1823.

Y. J. Chao, L. X. Xie and W. Cao, presented in part a confrence on Key Engineering Materials, Bali, March, 2014. J. Hassanzadeh, H. A. Al Lawati and I. Al Lawati, Analytical chemistry, 2019, 91, 10631-10639.

M. Wang, Y. Kong, Y. Li, Y. Huang and A. Fan, Analytical Methods, 2019, 11, 1317-1323.

M. R. Jones and K. Lee, Microchemical Journal, 2019, 147, 1021-1027.

H. Sun, H. Wang, W. Bai, L. Bao, J. Lin and Y. Li, Talanta, 2019, 191, 350-356.

A. G. Alapont, L. L. Zamora and J. M. Calatayud, Journal of pharmaceutical and biomedical analysis, 1999, 21, 311317.

W. Ruengsitagoon, S. Liawruangrath and A. Townshend, Talanta, 2006, 69, 976-983.

M. Iranifam, S. Khodaei and M. Saadati, Microchemical Journal, 2019, 146, 850-855.

S. L. C. Ferreira, R. E. Bruns, E. G. P. da Silva, W. N. L. Dos Santos, C. M. Quintella, J. M. David, J. B. de Andrade, M. C. Breitkreitz, I. C. S. F. Jardim and B. B. Neto, Journal of chromatography A, 2007, 1158, 2-14.

M. Kasiri, H. Aleboyeh and A. Aleboyeh, Environmental science \& technology, 2008, 42, 7970-7975.

J.-S. Kwak, International journal of machine tools and manufacture, 2005, 45, 327-334.

A. Khataee, Polish Journal of Chemical Technology, 2009, 11, 38-45.

D. Obeng, S. Morrell and T. Napier-Munn, International Journal of Mineral Processing, 2005, 76, 181-192.

A. Khataee, M. Fathinia, S. Aber and M. Zarei, Journal of hazardous materials, 2010, 181, 886-897.

F. Rigas, V. Dritsa, R. Marchant, K. Papadopoulou, E. Avramides and I. Hatzianestis, Environment international, 2005, 31, 191-196.

M. Ahmadi, F. Vahabzadeh, B. Bonakdarpour, E. Mofarrah and M. Mehranian, Journal of Hazardous Materials, 2005, 123, 187-195.

T. Rajmohan and K. Palanikumar, Measurement, 2013, 46, 1470-1481.

X. Li, X. Xu, D. R. Albano and T. You, Analyst, 2011, 136, 5294-5301.

V. Hamedpour, R. Leardi, K. Suzuki and D. Citterio, Analyst, 2018, 143, 2102-2108.

Minitab 17 and Statistical Software (2010), PA: Minitab. D. Chen, H. Wang, Z. Zhang, L. Ci and X. Zhang, Spectrochimica Acta Part A: Molecular and Biomolecular Spectroscopy, 2011, 78, 553-557.

D. Yang, Y. He, Y. Sui and F. Chen, Analytical Methods, 2016, 8, 7272-7278.

P. E. Imoisili and T.-C. Jen, Journal of Materials Research and Technology, 2020, 9, 8705-8713. 
M. H. Álvarez-Hernández, G. B. Martínez-Hernández, F. Avalos-Belmontes, M. A. Castillo-Campohermoso, J. C. Contreras-Esquivel and F. Artés-Hernández, Food Engineering Reviews, 2019, 11, 159-183.

47 T. Moreira, W. Blanca, L. Gundim, I. Castro and A. Medeiros-Ronchi, Arquivo Brasileiro de Medicina Veterinária e Zootecnia, 2019, 71, 1497-1505.

48 M. Kato, M. Yamada and S. Suzuki, Analytical chemistry, 1984, 56, 2529-2534.

49 Z. Li, M. Feng and J. Lu, Microchemical journal, 1998, 59, 278-283.

50 F. Marcos, H. Luiz, F. Orlando, C. Fernando and S. Ronaldo, Current Analytical Chemistry, 2009, 5, 305.

51 C. T. J. Alkemade, W. Snelleman, G. Boutilier, B. Pollard, J. Winefordner, T. Chester and N. Omenetto, Spectrochimica Acta Part B: Atomic Spectroscopy, 1978, 33, 383-399.

52 Y. M. Oskoei, N. Bagheri and J. Hassanzadeh, Microchimica Acta, 2015, 182, 1635-1642.

53 F. Xiangli, W. Wei, Y. Chen, W. Jin and N. Xu, Journal of membrane science, 2008, 311, 23-33.

54 S. M. S. Shahabadi and A. Reyhani, Separation and Purification Technology, 2014, 132, 50-61.

55 P. Onsekizoglu, K. S. Bahceci and J. Acar, Journal of Membrane Science, 2010, 349, 225-230.

56 X. Yi, W. Shi, S. Yu, X. Li, N. Sun and C. He, Desalination, 2011, 274, 7-12.

57 N. Abdel-Ghani, A. K. Hegazy, G. El-Chaghaby and E. C. Lima, Desalination, 2009, 249, 343-347.

58 H. Liu, Y. Hao, J. Ren, P. He and Y. Fang, Luminescence: The journal of biological and chemical luminescence, 2007, 22, 302-308.

59 J. P. Wang, N. B. Li and H. Q. Luo, Spectrochimica Acta Part A: Molecular and Biomolecular Spectroscopy, 2008, 71, 204-208.

60 S. Bouatra, F. Aziat, R. Mandal, A. C. Guo, M. R. Wilson, C. Knox, T. C. Bjorndahl, R. Krishnamurthy, F. Saleem and P. Liu, PloS one, 2013, 8.

61 K. Varma, Res Rev J Chem, 2016, 5, 143-154.

62 E. Blaurock-Busch, Occup. Med. Health Aff, 2016, 4, 23296879.1000245.

63 I. I. Koukli, A. C. Calokerinos and T. P. Hadjiioannou, Analyst, 1989, 114, 711-714.

64 R. Săndulescu, S. Mirel and R. Oprean, Journal of pharmaceutical and biomedical analysis, 2000, 23, 77-87. 